\title{
大学化学课程思政的现状与应对策略
} 基于学生视角的探讨

潘向强 ${ }^{1,{ }^{*}}$, 龙思祈 ${ }^{2}$, 苍宇杰 ${ }^{1}$, 李璟 ${ }^{1}$, 赵蓓 ${ }^{1}$, 张正彪 ${ }^{1}$

1 苏州大学材料与化学化工学部, 江苏苏州 215123

2 苏州大学政治与公共管理学院，江苏苏州 215123

摘要: 教育发展新形势下, 高校思政教育面临新的需求和挑战。本文围绕化学学科特点, 以学生视角为出发点, 探 讨大学化学中的课程思政问题, 并提出若干应对策略。要深入推进课程思政, 应在教学内容中, 考虑学生的价值诉 求, 提升价值导向的针对性; 在教学评价中, 搭建师生沟通的渠道, 提升评价活动的精准性, 增强学生对课程思政 的认同度; 在学生层面, 转换学生的学习动机, 有效传递教学内容。

关键词: 化学专业; 课程思政; 教学评价

中图分类号: G64; O6

\section{Discussion on the Current Situation and Strategies for the Course Ideology and Politics in University Chemistry: From the Perspective of Students}

\author{
Xiangqiang Pan ${ }^{1, *}$, Siqi Long ${ }^{2}$, Yujie Cang ${ }^{1}$, Jing Li ${ }^{1}$, Bei Zhao ${ }^{1}$, Zhengbiao Zhang ${ }^{1}$ \\ ${ }^{1}$ College of Chemistry, Chemical Engineering and Materials Science, Soochow University, Suzhou 215123, \\ Jiangsu Province, China. \\ ${ }^{2}$ College of Politics and Public Administration, Soochow University, Suzhou 215123, Jiangsu Province, China.
}

\begin{abstract}
Under the new situation of education development, curriculum ideological and political education in colleges and universities faces new demands and challenges. Based on the view of students and the characteristics of chemistry science, this paper discusses the ideological and political problems in university chemistry, and proposes a number of corresponding solutions. In order to further promote the course ideology and politics, we should consider the students' value demands and improve the pertinence of the value orientation in the teaching contents; in the instructional evaluation, we should set up the communication channels between teachers and students, improve the accuracy of the evaluation activities, and enhance students' recognition of the course ideology and politics. As for the students, delivering the teaching content effectively can be achieved by changing students' learning motivation.
\end{abstract}

Key Words: Chemistry major; Course ideology and politics; Teaching evaluation

\section{1 引言}

课程思政作为一种新的教育理念, 立足学科专业发展的要求, 通过挖掘各类课程的思想政治教 育资源, 实现育人维度的价值关照。在全国高校思想政治工作会议中, 习近平总书记强调: “要坚

收稿: 2021-05-06; 录用: 2021-06-21; 网络发表: 2021-07-01

“通讯作者, Email: panxq@suda.edu.cn

基金资助：2020 年苏州大学课程思政教学团队及示范课程资助项目：高分子化学(双语) 
持把思想政治工作贯穿教育教学全过程, 实现全程育人、全方位育人。” 要求把握学生发展需求, 遵循 “教育规律、思想政治工作规律、学生成长规律”, 将普遍性的教学方式和学科的特殊性结合, 提高课程思政的精细化水平 ${ }^{[1]}$ 。

课程思政开展以来, 面向不同学科的实施建议和实施经验不断涌现。宏观层面上, 着力建全组 织机制。首先, 在学校层面的顶层设计上, 发挥党委总揽全局的作用, 构建部门协同合作的组织体 系; 其次, 在课程体系中, 围绕专业顶层设计和专业培养要求, 挖掘核心课程中的思政元素, 对课

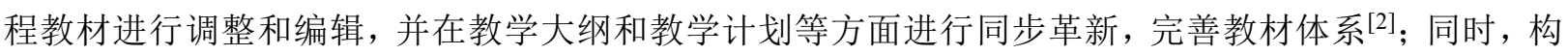
建集体备课制度和学科交流合作机制, 为各学科教师提供交流和借鉴的平台 ${ }^{[3,4]}$; 再次, 通过在考试 中设计科学思维和科学素养的问题、对学生发放调查问卷等方式, 以学生回答的正确率、课堂出勤 率量化指标等对思政教学效果进行评价 ${ }^{[5]}$; 微观层面上, 以教师为关键点, 围绕教师素养、教学模式 和教学内容三方面展开。在教师素养层面, 提升教师育人意识和思政素养, 充分调动专业课教师在 课程思政实践中的主动性 ${ }^{[6]}$; 在教学模式层面, 借助互联网课程资源和第二课程, 即社会实践课, 延 续课程思政的教育 ${ }^{[7]}$; 在教学内容层面, 通过在课程的知识体系中有计划地融入社会主义核心价值 观、家国情怀、传统文化等因素, 构建完整的课程思政脉络 ${ }^{[8]}$ 。

课程思政开展以来, 在宏观层面和微观层面都取得一定成效, 但在价值导向、评价机制的建设 中缺乏对学生现实需求的考虑, 导致教学效果针对性不强, 学生对课程的认同度不高。本文以大学 化学课程为例, 通过学生视角分析 “课程思政” 面临的问题, 探寻切合学生需求的解决路径, 对于 深入推进课程思政具有现实意义。

\section{2 大学化学思政教育中存在的问题}

\section{1 课程思政在价值导向上的针对性不足}

新时代背景下, 社会文化多样化发展, 网络媒体多元化进步, 大学生了解外界信息的渠道增加, 但同时获得的信息也更为复杂。大学生作为初步独立的群体, 个人的价值观仍未完全形成, 对专业 领域和社会重点问题的了解少，相较于长远发展，更注重于短期发展。

以化学专业学生为例, 部分学生在学习有机化学课程的过程中, 没有投入足够的时间和精力去 理解有机化学反应的机理和反应间的相互关系, 只满足于快速记忆反应式以实现应试的目的。因此, 学习动机以外部动机为主。这种弱内在动机阻碍了学生深入了解知识板块的内在联系和在实践中的 运用, 学生 “只知其然, 不知其所以然”, 没有把握学科的思维方式, 在解决具体的工作任务中很 难胜任。最终在职业选择时, 所掌握的专业知识和经验不足以帮助自身确定合适的职业方向, 容易 陷入职业迷茫; 另一方面, 学生对待学习的功利性过强, 可能导致学生在政治信仰和价值选择上也 逐渐功利化, 出现价值观扭曲、政治信仰模糊等问题。目前, 课程思政中的思政内容主要体现为爱 国主义、环保主义、优秀传统文化等元素, 但随着社会环境和学生意识的变化, 仅通过这些思政元 素开展价值教育并不足以解决大学生群体中出现的新问题, 思政内容缺乏在价值导向上的针对性, 与大学生需求的契合程度不足。因此在价值导向上不仅要坚持理想信念教育首要地位, 把社会主义 核心价值观教育融入课堂全过程, 还要针对学生价值诉求, 聚焦大学生群体中出现的新问题, 兼顾 社会责任意识教育、科学精神教育, 提高思政内容的指向性。

\section{2 课程思政的评价机制尚不完善}

在课程思政的评价机制方面, 评价方式以量化评价为主, 质性评价所占比重小, 使实践过程中 的问题难以得到细致的反馈, 一定程度上忽略了教学的动态过程。针对质性评价, 则以一维单项评 价为主, 多从学生层面对教学过程给予评级, 评价主体缺乏多元性。并且在质性评价中, 评价多为 单向评价, 师生之间缺乏交流沟通的渠道, 学生可能对教学产生误解, 教师也难以了解学生的具体 需求，评价制度不能充分发挥正向反馈作用。

在教师层面, 目前的考核体系依然主要针对教师的科研成果, 反映教学效果, 尤其是课程思政 
教学效果的指标不多, 教师创新课堂的外部动力不足。课程思政是新形势下的软课题, 如何评价还 需探索。

\section{3 针对课程思政的开展, 提出建设性建议}

\section{1 提升教师素养, 优化教学内容, 增强价值导向的针对性}

课堂作为教师和学生最直接、密切接触的活动场所, 是有效推进课程思政的良好载体, 课程思 政的开展应利用好课堂这一主要渠道, 实现价值引导、知识传授的目的 ${ }^{[1]}$ 。

亚里士多德在《形而上学》的开篇就写道: “每一个人在本性上都想求知。” 化学学科的学生 不会从根本上排斥思政教育, 相反, 思政教育和化学专业内容表面上差异较大, 在学生之前的学习 过程中鲜有直接涉及, 合适的课程思政能带给学生更多的共鸣和新鲜感。而学生对思政教育产生厌 倦感, 往往是由于教师孤立的说教和刻板的言辞难以对学生产生足够的吸引力。“传道者首先要名 道信道”, 所传之道就是中国特色社会主义的建设。课程思政的开展, 首先要让教育者先受教育, 教师通过学习关于课程思政开展的工作意见、政策指导, 阅读核心教学期刊、社科期刊, 借助学习 强国、央视新闻媒体等多种新媒体渠道, 理解课程思政的内涵和开展方法, 明确立德树人、教书育 人的教学目的, 明确教育在社会主义现代化建设中的作用。只有在提高自身思政理论水平的基础 上, 才能适当地开展思政教育, 以充沛的知识和正向的价值观教育塑造学生, 以理服人, 以情感人 ${ }^{[9]}$ 。 同时, 教师还需积极了解化学专业领域的前沿动态, 提升自身专业水平, 通过挖掘思政理论和专业 理论的内在关联, 将专业知识与课程思政的内核灵活地联系起来。化学课程内容突出理论性, 课程 内容可以挖掘的思政事例较多, 但是较为分散, 事例所涉及的价值维度也较窄, 不似社科类课程系 统性强。要在理论性较强的化学课程中将思政内容和专业内容融会贯通, 教师首先应选择恰当的理 论知识进行设计 ${ }^{[10,11]}$ 。在选择的依据上, 以两个中心为主要依据, 即以化学知识体系为中心, 以学 生为中心。以化学知识体系为中心, 强调教学设计是围绕化学内容进行思政设计, 而不是以化学内 容贴合思政; 以学生为中心, 就是在对理论知识进行思政设计的过程中, 特别是授课的初期, 即学 生对课程的新鲜感较强的时期, 充分考虑学生的主体需求, 教师可以将专业知识和社会实践问题有 机结合, 迎合学生的学习特点, 便于学生接受。在此基础上, 加入教师的实践经验和对专业发展的 理解帮助学生勾勒职业远景, 清晰地剖析行业的短板和卡脖子问题, 憧憬未来行业发展的多种可能 性, 激励学生在化学领域执着追求。并且, 进一步地将社会主义核心价值观和个人价值的实现相结 合, 使学生真正意识到通过专业知识建设中国特色社会主义的责任, 将个人发展与国家发展的未来方 向紧密联系。

例如, 在讲授化学热力学时, 教师可以将热力学第二定律与第二类永动机相结合。在当前能源 危机的背景下, 人们开始基于热力学第二定律, 研究第二类永动机的可能性。热力学第二定律早已 提出, 但根据现实需求, 人们不断对已有结论提出质疑, 由此启发学生对真理的探索是一个永不止 步的过程, 应基于现实需要不断追求真理; 并且第二类永动机从物理角度讨论化学问题, 通过学科 交叉解决现实问题, 可以引导学生在学习化学的同时, 加强自身对化学相关领域的了解, 拓宽思考 问题的维度; 最重要的是, 这一事例将理论知识和实际应用联系起来, 学生既了解了化学理论, 又 认识了化学理论如何指导实践, 让学生看到了化学未来的发展空间和社会对化学提出的需求。

\section{2 创新教学评价制度}

课程思政的有效落实, 不仅需要优化教学内容, 还需要进一步创新教学评价制度。只有完善教 学评价制度, 才能使实践中的问题得到良好的反馈和解决, 为教师改进教学提供可能, 进一步提升 教学质量。教学评价作为对教师及其教学行为进行评价的过程, 其目的并不是通过评分对教师的教 学活动进行量化评判, 而是搭建教师与不同主体沟通的桥梁。对评价客体教师而言, 评价是为了提 出和改进教学中的问题, 提升教师的教学能力, 从而促进学生的发展, 最终推进社会主义现代化建 设。教师深刻认识教评的意义, 有助于教师在接受他人的评价时减少偏见, 客观地接受不同主体的 
建议 ${ }^{[12]}$ 。对主要评价主体学生而言, 教评的质量与自身的发展息息相关, 如果把教评作为发泄不满 的渠道或报复教师的手段，不仅会使教师受到不公的评价，自己也将成为受害者。

评价方式上, 目前的评价制度包括 “量性” 和 “质性” 两种基本评价方式, 但过于强调定量研 究的方法, 如着重课堂出勤率, 学生毕业论文优秀率等指标。教学在过程和影响上都具有持续性, 过于注重定量方法忽略了教学的动态过程, 不利于对复杂的教学进行分析。因此, 评价方式应以 “质 性” 评价为主, 通过了解教学的动态过程, 在微观层面对教育现象进行细致的描述和分析; 同时兼 顾 “量性” 评价, 凭借标准化的数据收集, 对教学进行相对准确的测量。

与 “量性” 评价方式不同, “定性” 研究工具没有统一的衡量标准, 针对不同评价主体的特殊 性, 需要提供不同的研究工具。学生作为直接参与教学的主体, 对教学具体实施状况有长期的、具 体的了解; 同时作为课堂的中心, 学生提出的诉求和建议能更好地帮助教师抓住授课中心, 有效地 开展教学。学生是评价主体中不可忽略的构成要素, 应重视学生在评价中给予的意见, 但也要注意 学生评价具有一定的片面性。

受知识和经验的限制, 学生不了解课程需要达到的教学目的, 更难以从宏观的视角认识课程在 整体的知识构架中的重要性; 同时, 学生欠缺对课程重难点的把握, 教师针对重点内容布置较多练 习时, 学生可能产生畏难、厌恶等情绪。另外, 学生人数较多, 为提高评价效率, 评价信息主要通 过问卷收集。学生作为被动提问的对象, 自身的表达欲望可能并不强烈, 在对不同的课程进行评价 时, 需要针对科目特点、教师差异提出具体的问题, 引导学生做出客观且详细的回答, 以人性化的 标准评价教师。为了使教评更全面、客观, 还需通过评价主体的多元化, 提高评价结果的准确性。 除学生外, 同系教师和专家也是评价主体中较为重要的部分, 二者熟悉课程内容, 具有教学经验, 可 针对课程目标、授课方式、教学内容等方面提出评价。但无论是学生还是同系教师, 评价都指向课 堂微观层面, 缺乏宏观层面评价, 院系学科负责人作为评价主体就较好弥补了这一缺陷。学科负责 人根据学校及学院的整体教学动态, 综合不同课程的教学特点, 为教师创新课堂提出新的思路, 同 时提醒教师注意一些普遍存在的课堂问题 ${ }^{[13]}$ 。由此, 通过综合以上评价主体, 结合问卷、听课记 录等多种方式，对课程思政的教学背景、过程、效果进行质性评价 ${ }^{[14]}$ 。

在教学过程的评价中, 教师填写问卷, 从主体的角度出发, 对思政内容的挖掘度、自身的课程 思政素养、职业素养等方面进行评价; 其次, 学生填写教学评价问卷, 以客体的角度出发, 对教学 内容的受众度、新颖度, 思政内容与课程的契合度等方面进行评价。由此, 教师可以通过学生反馈 与教师自评的对照, 横向了解课程预期与课程实践的落差点, 进而有针对性地与学生进行交流, 探 究思政内容的改进方向; 此外, 教师还可以综合不同时期或不同班级的学生反馈, 纵向对比课程内 容在改进后是否达到良好效果。与此同时, 同系教师和学科负责人可以通过不定期听课的方式, 随 机调查思政内容在整体课程中的落实程度, 并与教师在课后开展交流。

在教学效果的评价中, 学生通过填写问卷, 对课程在价值观、职业观、人生观等方面对自身的 影响进行评价。问卷内容主要考查学生是否能正确认识世界和中国发展趋势, 是否能运用辩证唯物 主义和历史唯物主义的观点分析问题, 是否勇于担当时代责任 ${ }^{[15]}$ 。教师则通过与学生的接触, 对学 生的学习态度、思政素养等方面展开评价。

评价是通过教师与不同主体的沟通优化教学的过程, 要实现有效的沟通, 不能仅具备单方面的 评价而缺乏反馈。评价主体通过观察获得的往往是表面的和感性的材料, 难以深入了解教师的思路, 给予的评价具有片面性。通过搭建教师的反馈渠道, 不仅调整了教师在评价中的被动地位, 减少误 解的产生，同时提升了评价主客体的参与度和评价的客观性，充分发挥评价制度的正向作用。

\section{3 转变学生学习动机, 使教学内容得到有效传递}

学习动机是指激发与维持学生学习的行为, 并使其行动指向目标。根据学习动机的来源, 可分 为内在动机和外在动机。内在动机是指引发和维持个体的活动, 并将其导向某个目标的内部驱动, 即个体对内在满足感的享受。外在动机则是一种引起活动的外部因素, 是个体对外在结果在乎的体 
现。外在动机能在特定的情况下推动学生的学习, 但难以构成学生长期的驱动力, 内在的成就感和 满足感不仅能成为学生的有效驱动力, 且有助于学生理性接受自身的失败, 缓解学习焦虑。在学习 过程中, 学生并不完全由外在动机或内在动机推动, 大多数情况下, 学生的学习动机是一种整合动 机 ${ }^{[16]}$, 这种观点认为学习动机是在个人需求的基础上, 即外在动机的驱动下与内在动机相适应, 从 而激发内在动机。

教学在狭义上定义为教师的教和学生的学的过程, 课堂内容和教学模式调整并不能完全实现有 效的课程思政, 还需要学生转变学习动机。二者是互相促进的关系, 没有学生对课堂的反馈, 教师 容易失去教学积极性; 缺乏高质量的课堂和正确的方向引导, 学生也难以对课堂产生兴趣。

因此, 要让学生参与到课程思政中, 首先要转变学生的学习动机。学生以外部动机为主要动机, 除了升学制度的因素, 整体的教育环境过度强调成绩等目的的重要性也对学生产生了影响。国外学 者研究认为: “当个体体验到来自团体或重要他人高的归属感时会自愿地内化其价值观或调节方 式 ${ }^{[17]}$ 。” 换句话说, 归属感是个体接受他人观念、内化动机的前提条件。教师作为与学生接触最为 密切和频繁的角色, 对学生的鼓励和期待能增强学生学习的动力和信心, 提升其课堂投入度和参与 度, 由此学生可更加有效地接收教师在传递的价值观念。

例如, 化学学习需要学生具备较好的推理能力和逻辑思维能力, 在遇到知识难点时, 学生可能 产生畏难情绪, 因一时的困难放弃探究知识点。此时教师可以适当鼓励学生不要因畏难而降低自我 要求, 学习不仅仅是为了掌握知识点, 更是为了提升自身能力, 未来更好地将所学运用于社会, 在 个人与社会的统一中实现价值。

\section{4 结语}

大学时期是学生价值观确立的关键时期, 在化学课程等专业课程中开展课程思政的重要性不言 而喻。课程思政首先需要教师提升自身思政素质, 明确德育的地位; 在课程设计中结合学生价值需 求和课程要求, 有选择性地将德育融入教学, 找准发力点, 以德施教, 使价值选择和德育实施都具 备针对性; 在教学的评价机制上从一维单向评价向多维多向评价转换, 通过搭建双向的评价渠道, 帮 助教师及时优化教学课堂; 同时转变学生学习动机, 增强学生内驱动力, 牢固树立社会主义价值观, 为现代化建设培养德才兼备的社会主义接班人。

\section{参 考 文 献}

[1] 关于加强和改进新形势下高校思想政治工作的意见. [2021-04-29]. http://www.gov.cn/xinwen/2017-02/27/content_5182502.htm

[2] 项波祺, 吴仰祺, 杨路萍. 黑龙江高教研究, 2020, 38 (4), 152.

[3] 高燕. 中国高等教育, 2017, No. 15, 11 .

[4] 陆道坤. 思想理论教育, 2018, No. 3, 64 .

[5] 罗仲尤, 段丽, 陈辉. 思想理论教育导刊, 2019, No. 11, 138.

[6] 刘清生. 江苏高教, 2018, No. 12, 91.

[7] 张乐, 张云霞. 中国高等教育, 2018, No. 1, 36 .

[8] 孙志伟. 思想政治课研究, 2019, No. 1, 93 .

[9] 王学俭, 石岩. 新疆师范大学学报(哲学社会科学版), 2020, 41 (2), 50 .

[10] 于子钧. 天津化工, 2018, No. 6, 51 .

[11] 王朝霞, 伍新燕, 窦清玉, 罗千福. 大学化学, 2018, 33 (4), 21.

[12] 申继亮, 刘加霞. 华东师范大学学报(教育科学版), 2004, No. 3, 44.

[13] 杨鸿. 高校课堂教学质量评价标准的研究[硕士学位论文]. 北京: 中国地质大学, 2006 .

[14] 任艳红. 高校教学评价制度的反思与重构[博士学位论文]. 西安: 陕西师范大学, 2011.

[15] 张树永. 大学化学, 2019, 34 (11), 4 .

[16] 陈笏, 仇妙琴. 现代教育论丛, 2010, No. 12, 37.

[17] 何明娟, 肖海雁. 山西大同大学学报(社会科学版), 2009, 23 (1), 87. 